\title{
The Authority Exercised by Nurses in Healthcare Institutions
}

\author{
Danelia Gómez-Torres, Karla Sofîa Gómez-Alcántara \\ Faculty of Nursing and Obstetrics, Autonomous University of the State of Mexico, Toluca, Mexico \\ Email address: \\ gomezdanelia@usa.net (D. Gómez-Torres),sofia33gom@gmail.com (K. S. Gómez-Alcántara)
}

\section{To cite this article:}

Danelia Gómez-Torres, Karla Sofia Gómez-Alcántara. The Authority Exercised by Nurses in Healthcare Institutions. American Journal of Nursing Science. Vol. 8, No. 5, 2019, pp. 232-238. doi: 10.11648/j.ajns.20190805.15

Received: May 27, 2019; Accepted: July 5, 2019; Published: August 28, 2019

\begin{abstract}
Modern management in institutions or organizations consists in the creation of an innovative mentality which focuses on permanent learning and sustains the growth of competitiveness and the achievement of goals. Thus the authority enjoyed by nursing in healthcare institutions aims to achieve changes, engendering behavior that enables collective interaction for the benefit for healthcare institutions. The present research aimed to reveal the manner and meaning in which authority is exercised by nurses in the course of their managerial activity in healthcare institutions. Methodology: Qualitative descriptive research in which participated twenty-three senior level nurse managers in healthcare institutions, with interviews conducted using a guide, based on the lead questions and, thus, the research objectives. The criteria for inclusion were that pariticpants had worked as Director of Nursing for more than two years. The data was collected in the managers' working environment, with the two dimensions - the meaning and type of the authority that nurses possess - selected from the most significant data and then analyzed and discussed in terms of Blumer's theory of symbolic interactionism. The results revealed the meaning of authority, which is symbolized as respect and discipline, while its exercise requires specific knowledge. The characteristics of the authority wielded by the nurse were also identified, with the moral value of the manager considered to be of the utmost importance. The types of authority exercised by nurses were identified as either formal or moral. The present study concludes that social representation and interaction are revealed as integral by the measurement of authority conducted here, where meaning is distinct to the essence and philosophy of the profession, as they are immersed in an indispensible component managerial and organizational communication.
\end{abstract}

Keywords: Nursing, Chief Executive Officers, Symbolic Interactionism

\section{Introduction}

In a health system, its hospitals and healthcare institutions are subject to new forms of management, using theories of intelligent organization and strategic planning. Modern management in institutions or organizations consists in the creation of an innovative mentality, focused on permanent learning, which fosters the growth of competitiveness and the acheivement of institutional objectives. This makes the use of new models of authority necessary, in which leadership is of vital importance and task delegation indispensible, due to the expansion of the responsibilities involved in the upper and/or lower management of nursing in healthcare institutions, in such a way that fulfillment of a role of this nature requires a foundation in management.

In their practice of governance, anyone performing a managerial role must demonstrate administrative knowledge taken from professional experience. Professional governance corresponds to processes and structures that give nurses autonomy, control and authority with regard to nursing practice in an organization [1]. Experience from real life shows that preparation for the role is necessary, given that candidates do not always have the specific competencies required for high level management.

Currently, there is a lack of knowledge about how nursing staff who wield authority as managers in hospital organizations delegate said authority, whether they select or train the person that will represent them and whether they evaluate the task that they give them. In light of this lack of knowledge, the present study pretends to determine the manner in which the nurse's manager exercises their authority within healthcare institutions and the meaning this 
reveals.

Symbolic interactionism [SI], as both a theory and a term, was first proposed by Herbert Blumer [2]. SI seeks to study human life through human interaction, which, combined with other interactions, forms social interaction, on which, in turn, is modeled the capacity for human thought, wherein meaning and symbols interact and condition people's actions. Therefore, human beings are able to modify or alter the meanings or symbols they use in their actions and interactions based on their interpretation of the situation.

According to Blumer and as shown by Valdivia [3], the theory comprises premises:

The process by which actors construct meaning; the actors' self as related to themselves; and, individual behavior is not determined by external macro forces - social structure, culture, status, social role, customs, values, institutions, social norms, social situation, etc.

The process premise - This theory aims to ascertain how people form the meanings of objects based on their interaction with other people and how they act in the presence of every object due to the meaning it has for the individual [4]. Therefore, meanings are not derived from mental processes and, even less, from isolated mental processes, but rather from the process of interaction, namely from co-existence and relationships with others. The main concern does not lie in the manner in which people mentally create meanings and symbols, and lies, instead, in manner in which they are learned during interaction in general and socialization in particular.

Meaning lies within the social act and can relate to any entity that the person perceives in their world and is, itself, constructed via premises. Based on their meaning for them, human beings act in relation to things: physical objects, such as a chair or tree; other human beings, such as their mother or a shop assistant; categories, such as friends or enemies; institutions, such as the government or the church; normative ideals, such as honesty or loyalty; the actions of others, such as orders or criticism; and, any other situation that a human being encounters in their daily life.

The process of interpretation undergoes two distinct phases. First, the actor indicates, to themselves, the things with which they are interacting, aiming to identify those things that have meaning for them. This interaction with oneself is not exactly an interaction among psychological elements, and is instead a state in which the person undergoes a process of communication with themselves. By virtue of this process, interpretation becomes a manipulation of meanings, in which people are able to modify or alter the meanings and symbols that they use in their actions as a result of interaction based on their interpretation of a specific situation. The interwoven strands of action and interaction constitute groups and societies [5].

Mead established key concepts for understanding the socialization process, among which are found the concepts discussed below. A fundamental aspect for SI is the importance of ordinariness in reaffirming the individual's reality. Dialogue with others helps a person to maintain their routine [4], by means of which they maintain their reality, added to this, there is, within society, both a subjective and objective reality, which do not mutually correspond and are not, thus, equivalent. Objective reality can be transformed into subjective reality and viceversa. According to this author, interaction cannot be seen simply as the automatic application of established meanings and is, instead attributable to a formative process in which said meanings are used and reviewed as instruments that guide and form the action [6]. Therefore, this theoretical approach enables reflection on the social meaning of the authority exercised by nurse managers in healthcare institutions, in terms of the manner of said execution and how they select, train and evaluate the subordinate to whom they have delegated a task.

\section{Method}

The present study was undertaken with a qualitative focus on a descriptive level, in that it specifies the properties and significant characteristics of the subjects of the research. This study followed a diachronic methodology, as this enables data to be collected without the application of a specific time frame and, in fact, at any moment, given that it draws on subjective data, describing and establishing relationships, further to selecting the most significant for the generation of new knowledge.

The research sought to ascertain the models of delegation employed by managerial authority in institutions forming part of the healthcare system in Mexico. The social actors in this research were identified as nurse managers (the highest managerial position in the profession), working in tertiary care hospitals in both Mexico City and the city of Toluca.

The methodological position of Blumer's symbolic interactionism indicates that scientific inquiry begins with the formulation of questions about the empirical world, their conversion into problems and, concomitantly, the attempt to solve them. For Blumer, scientific analysis, therefore, required clear elements of analytical discrimination isolated from the relationships between the elements, thus emphasizing the need to be familiar with the problem (which he refers to as the portion of the empirical world in which the research problem is found). Ethnomethodology was used as the methodology of the present study.

The inclusion criteria were that participants had worked as directors of nursing or head nurses in healthcare institutions for more than two years, with the objective of analyzing the characterization of the manner in which they exercise their authority. None of the interviews was eliminated.

Validity and reliability are upheld, as proposed by Díaz [7], while reliability is ensured via the application of ontological criteria through the rigorous adherence to the theory of symbolic interactionism, with the objective of studying human life and interaction. This theory aims to ascertain how people form meaning from objects based on their interaction with other people, and how they act in the presence of each object in terms of the meaning it has for them [4]. Interactionism is characterized by favoring 
qualitative research, as it offers the possibility of understanding how interpretation is constructed in texts and, therefore, how their meaning is oriented [8]. In light of the foregoing, the study object, namely the manner in which authority is exercised by nurse managers in healthcare institutions, given the fact that delegation necessarily involves interaction, is highly applicable.

The instrument comprises a guide for a semi-structured interview of nine questions generated from the lead questions, themselves formulated from the research objectives. Finally, an open question invites participants to express additional ideas, in order to obtain truthful and significant results.

Once the research instrument had been established, the data were collected by means of interviews and direct observation, with the interviews recorded, with the consent of the participants, and then transcribed.

Content analysis was the method used to analyze the findings and comprised the following phases: pre-analysis; exploration; the grouping of material; and, the final treatment.

The pre-analysis involved the repetitive, exhaustive and critical reading of the transcripts, with the aim of capturing the most relevant data, and led to the selection of those fragments containing information pertinent to the type of research (units of meaning), thus constituting the corpus of the present study. The entirety of the material was then explored via occurrence and concurrence analysis conducted on the themes, based on which, the content analysis generated an organizational line on the theme of authority, divided into sub-categories. This facilitated the selection of units of greater meaning for the systematic analysis of the data.

The grouping gathered together the contributions to the theme, with the association of the information enabling them to be labeled by category according to the lead questions, and was carried out according to its similarity and complementarity via the chromatic technique. After this stage, the final treatment was carried out on all of the content generated by the interviews, leading to new thematic groupings and re-groupings by affinities, according to the testimonies, thus enabling the visualization of the response to each lead question, in order to interpret the meaning of the findings.

These groupings were discussed as they emerged, with, firstly, each category categorized, according to that established in the scientific methodology for qualitative studies, in order to contrast the emprirical data taken from the categories with the theoretical text and then arrive at a logical reasoning. This is used to determine the meaning and manner of exercising authority as demonstrated by nurse managers working in healthcare institutions, thus enabling the results to be presented consecutively by means of categories and subcategories.

Ethical aspects of the research. When research involves people it should be developed in accordance with the criteria set out in Article 100 of the Mexican General Health Law, which states that subjects must provide their written consent to participate in the research and are fully aware of the consequencies that this could have.

Respecto al nivel de riesgo en la investigación, debido a las características de objetividad e imparcialidad de la investigación, esta se considera sin riesgo, según la clasificación estipulada, ya que solo se realizaron entrevistas, porque según lo estipulado en el artículo 16, de la misma ley: esta considera como investigación sin riesgo aquella donde la probabilidad de que el sujeto de investigación sufra algún daño como consecuencia inmediata o tardía del estudio.

Due its characteristics of objetivity and impartiality, the present research is considered without risk in accordance with the classification stipulated, in that it solely involved interviews. According to Article 16 of the same law, research is considered without risk when the probability that the subject of the research suffers damages or injury as an immediate or subsequent consequence is null, since they are studies that employ techniques and methods of retrospective documentary research and those in which no intervention or intentional modification is made in the physiological, psychological and social variables of the individuals participating in the study.

The present research project was put before the ethics committee presiding over matters related to nursing at the Health Sciences Research Unit of the Coímbra School of Nursing in Portugal, which found, as set out in ruling No. 222-10/2014, that it complied with the accepted ethical norms.

To ensure compliance with the legislation, the bioethicsrelated aspects of this research were based on that set out in the General Health Law, which, in Title Two, Chapter One, Article 16, establishes that, in research conducted with human beings, the privacy of the individual subject of the research must be protected. In order to comply with this section of the law, participants are identified with a fictitious name of an institution in order to preserve their anonymity.

\section{Results and Discussion}

The results of the study are presented in categories (in some cases divided into sub-categories): authority; characteristics of the authority; types of authority; delegation of authority; selection of authority, with the sub-categories professional requirements of the delegatee, social requirements of the delegatee and leadership requirements of the delegatee; preparation of the delegatee, with three subcategories - induction to the role, training of the delegatee and training activities; responsability of the delegatee; limits; and, evaluation of the delegatee.

In order to approach themes related to the meaning of authority, is important to learn about the actor exercising authority, as well as the symbols and meanings that present in this context. Giving meaning requires a symbol, namely a class of objects used for thought, communication and representation [9]. A symbol functions by means of variables and, for the purposes of this research, begins by identifying 
the symbol or representation of the authority figure, mainly in the area of nursing, taking into account the voices of the experts in management roles, who state the following with regard to authority:

It symbolizes respect, discipline, knowledge and responsibility in the line of work to be followed (E-2).

Authority is power, it is a great commitment to obtaining good results or favorable responses within the institution (E-9).

As expressed by the participants, when demonstrating that which symbolizes authority, it is related to their daily exercise of moral and cognitive qualities. Meanings result precisely from the interaction between human beings and others, wrapped up in a world where the symbols present in the interaction enable the individual to receive information about themselves from others and, most importantly, anticipate how others will react to their behavior [6]. In this case, the authority applied in the area of nursing comprises the application of power, dominion or command. The daily exercise of authority reveals glimpses of knowledge of discipline and the implementation of human values, characteristics most representative of management that make it a practice that helps and motivates collaborators.

\subsection{Meaning of Authority}

Meaning is the representation of a thing, person or image. If signs are found in the culture, meanings become a circumstantial part of it. The meanings constructed via the internalization of higher psychological processes, whose value lies in the ability to create artificial stimuli that, finally, become immediate causes of our behavior [10]. Some of the most representative authority symbols have been mentioned, but questions of the meaning of authority have not yet been answered. When faced by conceptualizations from years ago, all forms of authority would expect to have immense power, one which, it seems, they may not possess. Authorities would expect the right to impose their will over others, regardless as to whether their judgments were correct [11]. On being questioned as to the meaning of authority, the participants' repsonses were as follows:

It is the figure which has highly established moral premises, with the knowledge and experience for determining the path to follow (E-5).

It seems to me that the contemporary manager must be more full of moral authority than power (...) it is a concept that involves all these humanistic, ethical, and moral aspects - related to personal and professional formation and life and professional trajectory - that one acquires over the course of their career (E-5).

The manner in which the meaning of authority is visualized has undergone a radical change, because it involves reason and contemporary experiential processes, as shown in the interviews. According to symbolic interactionism, human beings act in relation to things, based on the meanings they have for them, converging on an understanding, by means of symbolic interactionism, of how people perceive, understand and interpret the world in society [12]. It could relate to any entity identified by the person: physical objects; normative ideals, such as orders or criticism; and, any situation that a human being encounters in their life. In this case, the meaning of authority is represented as a figure providing guidance to the best path by presenting premises drawn from disciplinary and universal knowledge, experience and moral qualities, and converting them into the model to be followed. Speaking from a distinct administrative perspective, other participants interviewed describe authority as follows:

A manager's faculty to administer, by means of an organization, descriptive knowledge, policies, institutional programs, the profession for which we are responsible, in this case nursing (E-6).

The faculty given to a manager to guide, organize and achieve political, institutional and professional objectives (E-6).

From the moment at which one is capable of leading a group of human professionals, in that authority is exercised and authority in that which it knows what to do (E-7).

Given the foregoing and congruent to interactionism, which alludes to meaning, authority lies within the social act, in which lies the capacity to predict probable behavior ${ }^{[3]}$. This leads to the conclusion that the meaning of authority lies not only in being a figure but also an act, a social act, a faculty or a capacity, useful for guiding, organizing and achieving an institution's objectives, a conclusion which leads to the understanding that meaning is derived more from the figure's act or activity than the figure on its own.

\subsubsection{Characteristics of Authority}

With regard to managerial action, knowledge and values are representative of management in nursing; however, there are other attributes which form the basis for the performance of nursing staff who wield authority. All authority must have certain attributes that motivate each of their subourdinates on interaction with them, in such a way that they are convinced and enabled to better perform their work. Among the attributes found to maintain this actor's performance is the communication undertaken by the authority with their collaborators.

\subsubsection{Knowledge for the Exercise of Authority}

Knowledge, generally, is distinguished by the concepts of knowing and familiarity, given that it is constituted by both. Knowledge is not given exclusively by knowing something but also by having familiarity with it. Saying that I know about something or someone has different implications to saying that I am familiar with it or them, in that familiarity precisely indicates having or having had personal and direct experience, namely to have been in contact with or familiar with something or someone. As knowing is conformed by propositions, it is possible to know something without being familiar with it, while it is not posible to say that I am familiar with something without having had direct contact with it [13].

The propositions comprising knowing can be transmitted uncoupled from direct experience, while familiarity is personal and untransferable. Knowledge, when referring to learning, relates to an entire process, involving different 
states, such as the physical, mental, cognitive, perceptual, and social, with the objective of personal growth and providing the meaning of being a person with a high academic level. On being questioned in relation to authority and its characteristics, the interviewees described the following:

The first essential element for empowerment is knowledge, knowledge of all policies and knowledge of all the processes that are carried out and which are immersed in nursing, it is very important that the nurse knows these processes perfectly well in order that they are able to act effectively, this would be the highest objective and also so that they can begin to become self-possessed when dealing with the other disciplines (...) (E-3).

A leader, a thoughtful person with abilities, attitudes, who likes service and is prepared, who has the tools from an academic perspective, who has the profile (E-4).

As a manager, observe how they are doing things and, based on this, also have knowledge from judgment, in order to be able to make judgments with regard to (...) (E-7).

In accordance with the foregoing, authority must present knowledge, which is converted into an important and necessary instrument in order to be able to act. In symbolic interactionism, one of the great phylogenetic achievements of the human being is its symbolic capacity. By means of the internal use of symbols, people come to define behavior and situations, thus giving them meaning. The individual, therefore, is considered neither simply a passive receptor of stimuli, nor a mechanical processor uncoupled from collective meaning, and is, instead, seen as an active constructor of meanings, where meaning is a social product, a creation emanating from and through an individual's defining activities, activities through which they interact [6]. All nursing authority must have knowledge or symbolic capacity which converts them into an active and dynamic constructor acting reflexively with their staff in a systematic and efficient manner. Thus, nursing staff who wield authority must also possess a high academic level as a qualifying characteristic for holding such authority in the first place.

\subsubsection{Values for Exercising Authority}

Authority can also be symbolized with values or normative ideals. Values, as such, do not exist and are solely entities. What does exist is the object that has value, made valuable by its properties - more so when of service to human beings. Thus, there are two meanings within the concept of value: the value of the object that is given by its natural qualities; and, the value attributed to the subject, which is based on qualities given to it by the person. An organization defines the principles and beliefs that act as the ideal to follow in everything that happens around it and which represents its culture. These principles and beliefs will be useful, at all times, for the institutional dynamic and strategic philosophy [14]. On being questioned, the participants discussed other elements, such as values:

To be just, well, justice simply applies the same elements for the benefit of all in the same way... (E-3).
Any of us managerial figures in nursing are commited to the institution; sure of our responsibility for the simple fact of being at the head of the profession at the profession head (E-9).

I have a great deal of communication with the staff, I try to be empathetic with them when something happens to them, in this way we look for solutions together (...) I mean I believe, the basis is communication with the staff and that there must be mutual respect (E-1).

The above comments reflect that, further to knowledge, the moral characteristics of all authority are presented in values, which are important symbols of human relationships. Learning what a symbol is, within interactionism, is only one of the processes that occurs in the human mind, while another process is learning to evaluate the symbols diferentially. Value judgments are either learned definitions of the attraction or rejection of something or beliefs about the value and importance of different phenomena.

These mental processes, such as the content of the symbols, explore human behavior, social roles, actions, individual perceptions and the interpretations people make from their reality [6]. Therefore, justice, commitment, responsibility, and respect, among others, could be the abstract objects, with moral principle, that characterize authority, where they are converted, by means of a value, into the principles and beliefs that, via value judgments, all ideals to follow must have. This process enables people to act and interact in a distinctively human manner. These ideas are broadly applicable to the area of management in nursing.

\subsubsection{Communication and Authority}

Communication is defined as a series of dynamic, fluid and constant steps in the transmission of a message that produces a response. It is also conceived as the exchange of information between two or more people [15], namely that, when we talk about communication, we are talking about process in which three elements - the emitter, the transmitter and the receiver - are principally interrelated in a process which occurs interpersonally. It is interpersonal when emitting verbal and non-verbal messages, in terms of the analysis of interaction and conversation, the patterns of the exchange of messages and signals. In this sense, communication is converted into a social bond among subjects exchanging innumerable meanings, enabling them to understand both themselves and others. If someone says something to someone by means of gestures and words, they establish a real and symbolic exchange of shared meaning, both individually and socially [16]. Therefore, to ensure institutional success and the achievement of objectives, one of the attributes all authority must have in relation to their subourdinates is the development of complete, clear and precise communication in all senses, as the participants describe:

The essential elements for empowerment are knowledge, acting effectively, maintaining communication with all areas and the transmission of experience (E-3).

Communication is indispensible for any of the organizations, in all the multidisciplinary areas, namely, 
maintaining effective communication among all the areas is fundamental (E-9).

Authority is given based on the goal to be achieved, on the activities, as well as the capacity for communication (E-3).

The capacity one has for managing, talking about and presenting arguments about aspects pertaining to nursing is well-known (E-8).

In light of the foregoing and according to symbolic interactionism, language is what enables the examination of action and the possibility of imagining different alternatives; however, it is not something personal or private, but is, instead, something that exists in relation to others. Communication is key for understanding thought expressed via speech and enables interaction, with individuals, who, on interacting with another, construct their own reality by means of the creation of symbols and establish meaning in each situation [6]. It is via interaction that communication is developed, while interaction occurs via communication; however, it is important that communication enables those exercising authority to develop the ability to think, giving form to and adapting information to institutional needs. This makes communication a fundamental competency in the good governance of institutions, oriented around the procedures of organizational communication, and considered an essential aspect for nursing professionals acting in a managerial capacity.

\subsection{Types of Authority}

The relationship between authority and power has been a persistent and inseperable duality, which has been modified over the passing of time, ceasing to be a ruling action and becoming a strategy developed with knowledge and values. It is a power relationship generated between a superior and a subordinate in order that the latter demonstrates changes in behavior and, moreover, increased activities, functions, performance and actions that cause a variety of conduct and behavior notable to the former and revealed in glimpses through a diversity of authority types.

\subsubsection{Formal Authority}

Formal authority is guided by solid arguments derived from rationality, essentially from a formal idea [11], and is imposed by obligation. It is received from a superior in order to be exercised over other people or subordinates ${ }^{[17]}$, as those interviewed for the present research describe when asked about the types of authority they develop:

Formal authority is that which we are given by the institution to exercise via the assignation of a role to be performed (E-7).

The type of authority that I have is formal, because it is sustained by an institutional appointment and supported by knowledge, values, abilities, and I start by saying that it is a linear type of authority because it depends on an organizational structure (E-9).

The above statements allude to formal authority, which, on validation via symbolic interactionism, speaks to various natures, among which are the natures of human society or the life of human groups, which are considered to be constituted by people in action. This action consists in the multiple activities that individuals undertake in their lives on meeting each other and in the manner in which they resolve the situations which present themselves [18]. This a nature in which thought is an instrument of adaptation and a product of interaction. Therefore, the formal type of authority is given in human groups in action, in order to undertake activities that require both a superior and subordinates, in such a way that the latter become the authority for other subordinates and are able to resolve situations which present themselves, at the same time exercising a type of linear authority and delegating roles.

\subsubsection{Moral Authority}

The solid arguments for moral authority are guided by moral agents, due to the fact that morality requires that agents act on the balance of moral reasons [11]. The reason behind the prestige of this authority is acquired by means of experience and ability, which provide certain knowledge in a specfic area, also influencing moral, social and psychological qualities etc. Thus, said authority acquires an indisputable superiority over others and identifies itself as authority with leadership [17], as the participants in the present study expressed on being questioned about the types of authority they most commonly develop:

Moral authority is, as we recognize, we act every day; we deal with and relate to other people (E-7).

A moral authority is for managing and, you could be leader, you could administer formal authority, but not be leader (E-4).

The above responses are related to another perspective that mentions interactionism - the nature of social interactions.

The life of a group necessarily presupposes that the interaction among its members and the activities of each person occur as a response to another person or other people or in relation to them. The importance of the interaction lies in the fact that it has a formative role in behavior. This means that human beings, on interacting with each other, must take into account that which they do, and they are forced to direct their own behavior on that basis. It is necessary to understand equally the objective and subjective conditions of human nature. It can be said that, in order to understand a certain phenomena, it is necessary to emerge and submerge oneself in the context of the singularity of each human being in the complex relationships, interactions and interrelationships they establish with themselves, the milieu and others [18]. It is from here that the self is visualized, denominated as the. It is the action of the individual in response to the social situation that exists within the individual's own behavior and is incorporated into their experience only after they have carried out the act. From this position, moral authority speaks to the nature of moral interactions. The interaction between its members and the actions of every person toward others has a formative role in behavior and is directed by agents, moral reasoning acquired via experience, the capacity for knowledge and moral qualities, with the objective of achieving leadership.

Therefore, personality itself is a combination of $I$ and $m e$ in the face of a social relationship or event. Namely, a nurse manager found to be undertaking managerial activities in an 
institution should demonstrate a combination of the two types of authority. The first type is moral authority by virtue of the strengths obtained via experience, knowledge and moral qualities sustained by leadership. A consequence of the first, thanks to these characteristics and the fact that a superior is assigned legal authority, the second is is given the title formal legal authority, with the assignation of which enabling the linear delegation of their authority and responsibility.

\section{Conclutions}

An aspect of the utmost importance for this research was that it reflected the representative symbols of power, and the authority this has for nursing. It is conferred as the power of authority, symbolized as a figure in action, which is acquired via its daily exercise, in which knowledge, discipline, experience and the application of human values are projected.

One of the important findings is that a manager must possess certain attributes for interacting with their subordinates, attributes that incentivize them in such a way that they are motivated and convinced in order to better carry out their work. Another attribute that sustains positive performance within the authority is the communication between a manager and theirsubordinates.

Future research in this area could use the administrative process as a framework. It is appropriate for the managerial environment, because the elements direct the application of a project in areas such as work processes, managerial roles, and the study of hierarchical levels, among others.

\section{References}

[1] Dos-Santos, José Luís Guedes; Erdmann Alacoque Lorenzini, (2015). Governance of professional nursing practice in a hospital setting: a mixed methods study. Rev. Latino-Am. Enfermagem, Scielo, Vol. 23, No. 6, 1024-1032. Disponible en: DOI: 10.1590/0104-1169.0482.2645.

[2] Rizo, M. (2014). Symbolic interactionism and the School of Palo Alto. Towards a new concept of communication. incom UAB, $8 . \quad$ Disponible

http://portalcomunicacion.es/downlonad/17.pd.

[3] Valdivia, Salas Blanca Irene, (2012). Experiencia Educativa: Interaccionismo social y vida cotidiana, Sistema de enseñanza abierta, Carr. Sociología, Univ. Veracruzana, Orizaba Veracruz, [citado 2015-10-24], 28 Disponible en: https://trabajosocialunam.files.wordpress.com/2014/02/interac cionismo-mead.pdf.

[4] Barrantes Umaña, Beatriz; Bolaños Bolaños, María Cristina, (2014). Spring whit a Broken Corner: psychosocial analysys of Mario Benedettís novel. Wímb lu, Rev. Electrónica de estudiantes Esc. de psicología, Univ. de Costa Rica. Vol. 9, No. (1), 7-28, 2014/ISSN: 1659-2107. Disponible en: DOI 10.15517/WL.V9I1.13516.

[5] Núñez, Duarrte Dick Lester (2018). Symbolic interactionism and its contributions to contemporary social theory, (febrero-
2018). Disponible en: línea: //www.eumed.net/2/rev/cccss/2018/02/interaccionismosimbolico.html//hdl.handle.net/20.500.11763/cccss1802interac cionismo-simbolico.

[6] Natera-Gutiérrez, Susana Ivette y Guerrero-Castañeda, Raúl Fernando, (2017) Symbolic Interactionism and Grounded Theory: a way for nursing, Rev Cultura de los Cuidados, 3 er. Cuatrimestre Año XXI - (49) 190-199 Disponible en: https://rua.ua.es/dspace/bitstream/10045/72942/1/CultCuid_49 21.pdf.

[7] Díaz Ll, G. (2010). The qualitative approach to research in the contemporary public health care, Revista Cubana de Salud Pública, Vol. 36, No. (1), 30-37.

[8] Tardivo, G. y Fernández, M. (2014). The symbolic interactionism in Italy and Spain: one road to go. Barataria, Revista Castellano-Manchega de Ciencias Sociales, (18), 4563: Disponible en: DOI: http://dx.doi.org/10.20932/barataria.v0i18.43.

[9] Gómez-Torres, D, Martínez, M. D., Madeira Alves, F. J. \& Frederico Ferreira, M. M. (2015). Authority of Nurse Managers to Resolve Conflicts: A Humanist Perspective. Revista de Enfermagem Vol. 4, No. (7), 41-49. Disponible en: http://dx.doi.org/10.12707/RIV15009.

[10] Aguilar-Correa, C. M. (2017). The Construction of the Psychological Meaning of the Concept of Professor by University Students of Pedagogy, Educare Electronic Journal, Vol. 2, No. (1), Enero-Abril, 1-24. Disponible en: DOI: $10.15359 /$ ree. $21-1.13$

[11] Shapiro, Scott J, (2013). Authority. Revista Derecho del Estado, S/V, No. (31) Julio-Diciembre, 5-77. Disponible en: https://revistas.uexternado.edu.co/index.php/derest/article/vie w/3603/3783.

[12] Villar García, María Gabriela; Mora Castellano, María del Pilar Alejandra, Maldonado, Reyes Aurora. (2018). An approach to qualitative research from the point of view of the discipline of design. Vol. 8 (16) disponible en: http://dx.doi.org/10.23913/ride.v8i16.357.

[13] Martínez M, C. A. (2015). Conocimiento Danzario. Cuadernos de Música, Artes Visuales y Artes Escénicas, Vol. 10, No. (1), 17-34. Disponible en: https://doi.org/10.11144/Javeriana.mavae10-1.coda.

[14] Rodríguez, G M M A, (2015). Assessment management practices. Negotium, Vol. 10, No. (30), 142-162. Disponible en: http://www.redalyc.org/articulo.oa?id=78238677009.

[15] Balderas Pedrero María de la Luz, (2015). Administración de los servicios de enfermería, $7^{\mathrm{a}}$. ed. Mc Graw Hill Education, México, 455.

[16] González M, LH. (2018). Sociología e interaccionismo simbólico. Rev. Universitaria, No. 23 - Enero/Junio. Disponible

http://educa.upnvirtual.edu.mx/index.php/hecho-en-casa/8hecho-en-casa/334-sociologia-e-interaccionismo-simbolico.

[17] Reyes Ponce Agustín, (2014). Administración moderna, Ed. Limusa, México D. F., 480.

[18] Álvarez-Gayou, (2010). Investigación cualitativa, Ciudad de México. 67. 